\title{
Nilai-nilai Spiritual dalam Upacara Tradisi Lopis Raksasa di Pekalongan
}

\author{
Maiyang Resmanti', Umu Hana Amini', 'Ufairoh Shoofii Abiyyi', Divani \\ Majidullah Syarief ${ }^{4}$, Asep Yudha Wirajaya ${ }^{5}$ \\ 1,2,3,4,5 Universitas Sebelas Maret \\ e-mail: maiyang.resmanti@student.uns.ac.id
}

\begin{abstract}
The giant lopis tradition ceremony in Pekalongan is the one of cultural events called syawalan which the event is interested by local and foreign people. The problem of this study is how lopis can attract wider community. This research is descriptive qualitative research with data collection techniques using observations, interviews, and literature reviews. The collected data are the fact of field collecting and information about spiritual values in Pekalongan giant lopis tradition. It during the process of making giant lopis which the makers are advised to purify themselves first, then the manufacturing process begins with reading basmalah, continued with selawat during making lopis, and ended with hamdalah. The spiritual values attached to lopis symbolize interreligious harmony, human relation with other relatives, and relationship with God. However, it in the process of cutting giant lopis are sincerity and a form of submission to God. Thus, it is the values that attract an attention of visitors both local and foreign, in addition to the large lopis shape.
\end{abstract}

Keywords : tradition, giant lopis, syawalan, Pekalongan, spiritual value

\section{PENDAHULUAN}

Salah satu tradisi yang hingga saat ini masih dilestarikan oleh masyarakat Kota Pekalongan sebagai warga pesisir, yakni upacara tradisi lopis raksasa. Tradisi tersebut diselenggarakan setiap lebaran idulfitri tepatnya pada tanggal 8 Syawal, sebagai ajang silaturahmi. Mulanya, tradisi ini berawal dari silaturahmi yang biasa dilakukan masyarakat setempat, yakni masyarakat Krapyak, Pekalongan saat lebaran dengan mengunjungi kerabat dan tetangga serta membawa bingkisan atau salah satu yang disajikan dalam rumah tersebut berupa lopis, kue khas yang terbuat dari olahan beras ketan.

Kemudian, berkembangnya zaman, diadakanlah perayaan untuk memperingati hari ke-8 Syawal atau biasa disebut dengan syawalan setelah berpuasa sunah 6 hari pada tanggal 2 sampai 7 Syawal. Lopis mengalami komodifikasi, mula-mula berukuran kecil kemudian menjadi berukuran besar dengan tinggi mencapai 2 Meter dan berat sekitar $2000 \mathrm{~kg}$ sehingga penganan yang muncul satu tahun sekali ini disebut dengan lopis raksasa. Selanjutnya, lopis raksasa itulah yang memiliki daya tarik pengunjung di luar Krapyak, bahkan luar Kota Pekalongan untuk menghadiri upacara tradisi tersebut.

Saat ini upacara tradisi lopis raksasa sudah merupakan acara tahunan yang diselenggarakan oleh penduduk Krapyak Kidul, Kota Pekalongan, Jawa Tengah. Bahkan, beberapa tokoh dan pejabat dalam negeri juga turut hadir dalam peringatan ini. Akan tetapi, tidak banyak orang mengetahui mengapa lopis memiliki daya pikat yang tinggi selain karena merupakan penganan khas Pekalongan. Tradisi yang sudah berjalan lama ini tentu memiliki nilai-nilai luhur dan filosofis, baik lopis sebagai objek maupun dari sisi pelaksanaan tradisi dalam rangka menjalin silaturahmi. 
Kota Pekalongan merupakan wilayah di pesisir utara Jawa. Selama ini Pekalongan terkenal dengan Kota Batik, tetapi budaya yang ada di Pekalongan tidak hanya itu saja. Salah satu budaya yang menjadi wisata adalah tradisi syawalan, perwujudan budaya Jawa di pesisir yang religius. Oleh karena itu, Pekalongan dikenal sebagai kota yang masyarakatnya menjunjung tinggi nilai-nilai religius dibuktikan dengan tradisi syawalan atau tradisi pada tanggal 8 Syawal yang dibalut dengan nuansa keislaman dengan menghadirkan lopis raksasa. Nilai-nilai keislaman ini tercermin dalam upacara tradisi lopis raksasa, baik saat proses pembuatan lopis raksasa maupun proses pembagian lopis raksasa kepada masyarakat atau pengunjung secara cuma-cuma. Secara tidak langsung lopis disimbolkan sebagai perekat tali silaturahmi antarwarga dan merepresentasikan religiusitas masyarakat.

Penelitian terkait tradisi lopis raksasa pernah dilakukan oleh Rosidin pada tahun 2016 yang mengkaji lopis raksasa melalui perspektif kerukunan antarumat beragama dikaitkan dengan nilai-nilai yang terkandung dalam lopis raksasa secara umum dan sejarah lopis raksasa ${ }^{1}$. Penelitian lain yang mengkaji lopis raksasa adalah Asmarani pada tahun 2019 mengulas lopis raksasa sebagai salah satu folklore dan penganan khas Kota Pekalongan yang memiliki makna filosofi'. Penelitian ini memiliki perbedaan dengan penelitian sebelumnya, yaitu pada fokus kajian berupa menganalisis nilai-nilai spiritual yang terkandung dalam upacara tardisi lopis raksasa baik saat proses pembuatan lopis, nilai-nilai spiritual yang melekat pada lopis, dan nilai-nilai spiritual lopis raksasa pada saat dibagikan kepada masyarakat.

\section{METODE}

Metode penelitian yang dilakukan adalah metode deskriptif kualitatif ${ }^{3}$, yaitu dengan menjabarkan temuan-temuan yang ada dengan maksud memberi wawasan mengenai nilainilai spiritual yang terkandung dalam upacara tradisi lopis raksasa. Dalam penelitian ini, terdapat dua sumber yang dijadikan acuan, yaitu sumber primer dan sumber sekunder. Sumber primer berupa studi pustaka dan wawancara di lapangan. Metode wawancara yang dipilih adalah wawancara semi terstruktur dengan narasumber tokoh agama setempat, budayawa Pekalongan, sejarawan Pekalongan, pakar kuliner khas Pekalongan, panitia penyelenggara lopis raksasa, dan perwakilan warga setempat. Sumber sekunder berupa observasi dan interpretasi secara hermeneutis.

Penelitian ini dimulai melalui studi pustaka untuk mencari refrensi terkait, seperti tulisan Rosidin (2016) dan Asmarani (2019) yang memberi pengetahuan mengenai lopis raksasa di Pekalongan, serta sumber lain berupa informasi dari arsip Pekalongan. Terdapat beberapa instrumen pendukung saat penelitian di lapangan, seperti petunjuk wawancara dan alat perekam audio video. Petunjuk wawancara berfungsi agar pertanyaan terfokus pada permasalahan. Alat perekam audio video digunakan untuk merekam wawancara dan observasi yang kemudian ditranskripsi. Lokasi penelitian yang dipilih adalah Gang 8, Krapyak, Pekalongan, Jawa Tengah karena di lokasi tersebut merupakan tempat diadakannya upacara tradisi lopis raksasa.

\footnotetext{
${ }^{1}$ R Rosidin. 2016. Tradisi Lopis Raksasa dalam Perspektif Kerukunan Umat Beragama di Kota Pekalongan. Al-Ulum, 16(1). https://doi.org/10.30603/au.v16i1.24

${ }^{2} \mathrm{R}$ Asmarani. 2019. Translating the Unique Folklore of Giant Lopis Feast And Giant Cone Megono In Pekalongan Syawalan Traditions. https://doi.org/10.2991/eltlt-18.2019.18

3 A. K Nuzuli. Spasialisasi Sony Music Entertainment Indonesia. Jurnal ILMU KOMUNIKASI, (2020), 123.
} 


\section{TEMUAN}

Kota Pekalongan merupakan salah satu kota yang berada di wilayah Jawa Tengah dan termasuk bagian dari jalur pantura atau pantai utara dengan ketinggian sekitar satu meter di atas permukaan air laut. Letak geografis Kota Pekalongan antara 6 50'42" Lintang Utara sampai dengan 6 55' 44" Lintang Selatan serta 109 37' 55” s.d. 109 42' 19" Bujur Timur dengan koordinatif fiktif antara 510.00 sampai $518.00 \mathrm{~km}$ membujur dan 517.75 sampai $526.75 \mathrm{~km}$ melintang. Berbatasan dengan Laut Jawa di bagian utara, Kabupaten Batang di bagian Timur, Kabupaten Pekalongan dan Batang di bagian selatan dan barat. Letak tersebut menjadikan Kota Pekalongan berada di antara wilayah yang memiliki kemiripan kekayaan alam dan budaya dengan sekitarnya ${ }^{4}$.

Termasuk salah satu kota kecil di dunia dengan luas kota sekitar $42.25 \mathrm{~km}^{2}$ dengan jarak terjauh dari barat ke timur kurang lebih $7 \mathrm{~km}$ dan jarak terjauh dari utara ke selatan kurang lebih $9 \mathrm{~km}^{5}$. Secara administratif, Kota Pekalongan dibagi menjadi empat kecamatan, yaitu Kecamatan Pekalongan Utara, Kecamatan Pekalongan Timur, Pekalongan Selatan, dan Pekalongan Barat.

Berdasarkan laman resmi Kota Pekalongan, Pelabuhan Perikanan Nusantara (PPN) Pekalongan pernah menjadi Pelabuhan terbesar di Pulau Jawa sehingga arus transportasi jalur kelautan termasuk dalam kategori tinggi. Banyaknya kapal-kapal yang berdatangan dari luar daerah menuju Pelabuhan Pekalongan menyebabkan banyak pula masyarakat dari luar daerah yang berdatangan ke Kota Pekalongan, baik dalam urusan bisnis atau ekonomi maupun penyebaran budaya.

Pekalongan adalah kota pesisir, salah satu kebudayaan yang ada di wilayah pesisir adalah budaya syawalan. Budaya syawalan merupakan perayaan hari ketujuh setelah lebaran idulfitri, tepatnya pada tanggal 8 Syawal. Syawalan di Kota Pekalongan membawa kebudayaan pesisir yang unik daripada kebudayaan pesisir lainnya. Biasanya, tradisi di daerah pesisir didominasi kegiatan yang berkaitan dengan budaya maritim, yaitu pesta di sekitar pantai dan laut, seperti syawalan di Demak, 1 Suro di Kabupaten Pekalongan, 1 Suro di Kabupaten Batang, dan beberapa wilayah pesisir lain dengan tradisi lomban, sedekah laut, nyadran atau sebutan lain yang memiliki kegiatan hampir sama. Syawalan di Kota Pekalongan merupakan campuran atau akulturasi antara budaya pesisir dan budaya agraris. Pemilihan tanggal 8 Syawal sebagai puncak pesta lantaran tanggal 9 Syawal masyarakat setempat yang notabene berprofesi sebagai nelayan mulai kembali melaut sehingga syawalan ini dijadikan pesta merayakan akhir libur melaut ${ }^{7}$, sedangkan budaya agraris diambil dari lopis yang merupakan olahan beras ketan. Beras ketan merupakan bagian dari hasil pertanian.

Lopis raksasa merupakan produk budaya pesisir berwujud makanan dari olahan beras ketan yang berukuran raksasa dan hanya dibuat setahun sekali ketika lebaran idulfitri di Kota Pekalongan bagian utara atau di wilayah Kelurahan Krapyak, Kecamatan Pekalongan Utara. Tinggi lopis raksasa bisa mencapai 2 meter dengan berat sekitar $2000 \mathrm{~kg}$. Pada tahun 2002, lopis raksasa ini mendapat rekor dari Museum Rekor Dunia Indonesia sebagai lopis terbesar. Budaya yang telah mengakar akan menjadi sebuah tradisi lantaran tetap dilanggengkan dan dilakukan secara turun-temurun dari generasi ke generasi.

\footnotetext{
${ }^{4}$ BPS Kota Pekalongan. 2021. Kota Pekalongan dalam Angka 2021. In BPS Kota Pekalongan (Ed.), Badan Pusat Statistik Kota Pekalongan. BPS Kota Pekalongan.

${ }^{5}$ Ibid

${ }^{6}$ K Anwar. 2013. MAKNA KULTURAL DAN SOSIAL-EKONOMI TRADISI SYAWALAN. Walisongo: Jurnal Penelitian Sosial Keagamaan, 21(2). https://doi.org/10.21580/ws.2013.21.2.253

7 Wawancara dengan warga setempat, Iwan Kurniawan, 6 Juni 2021
} 


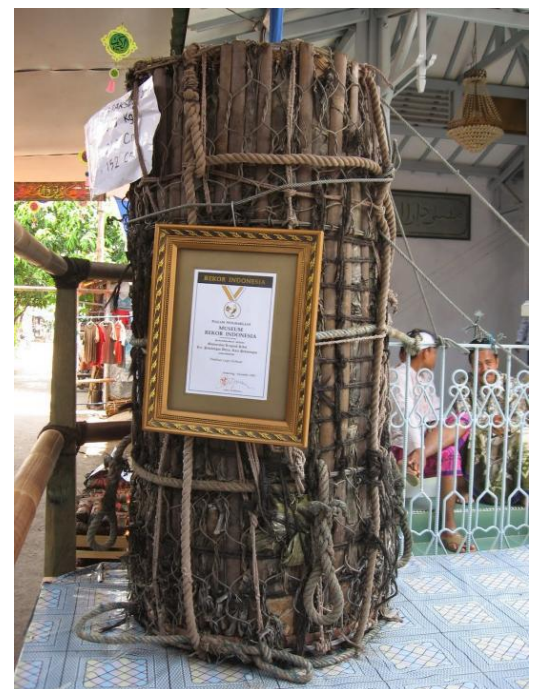

Gambar 1. Lopis Raksasa mendapat Rekor MURI pada tahun 2002 Sumber: internet

Tradisi syawalan yang dihelat pada 8 Syawal di Kota Pekalongan dimulai dari sejarah ulama setempat yang bernama KH. Abdullah Sirodj. Sekitar tahun 1880, masyarakat Krapyak banyak yang melakukan puasa sunnah bulan Syawal pada tanggal 2 sampai tanggal 7 Syawal. Puasa sunnah ini sangat dianjurkan oleh KH. Abdullah Sirodj sehingga hampir seluruh masyarakat Krapyak berpuasa. Masyarakat yang ingin bersilaturahmi di Krapyak pada tanggal 2 sampai 7 Syawal enggan lantaran tuan rumah sedang berpuasa sehingga secara konvensi masyarakat dari luar Krapyak bersilaturahmi pada tangal 8 Syawal sebagai wujud penghormatan kepada tuan rumah ${ }^{8}$.

Lopis merupakan pengangan yang tidak mudah basi. Lopis yang dimasak minimal 8 jam, dapat bertahan sekitar 3 hari. Lopis merupakan pengangan khas yang disajikan kepada tamu pada saat lebaran idulfitri. Oleh karena itu, makanan ini diminati para tamu luar kota maupun dalam kota yang bersilaturahmi di wilayah Krapyak, Pekalongan, sebagai oleh-oleh. Tradisi lopis ini makin terkenal sampai ke berbagai daerah. Mula-mula lopis berukuran kecil disediakan secara cuma-cuma di lokasi tertentu untuk para tamu yang tidak memiliki teman atau kerabat di Krapyak, tetapi ingin berkunjung ke Krapyak. Makin ke sini, lopis mengalami komodifikasi berupa ukurannya makin besar dan menjadi tradisi tahunan. Awalnya, lopis raksasa bersumber dari dana swadaya masyarakat setempat, melalui sumbangan beras ketan dan bahan-bahan lain. Setiap rumah memberi bantuan satu gelas beras ketan. Akan tetapi, pada saat ini pemuda setempat telah menggaet pemerintah kota dan mendapat bantuan dana dari pemerintah kota ${ }^{9}$.

${ }^{8}$ R Rosidin, op. cit

${ }^{9}$ wawancara KH. Zainudin Ismail, 13 Juni 2021 


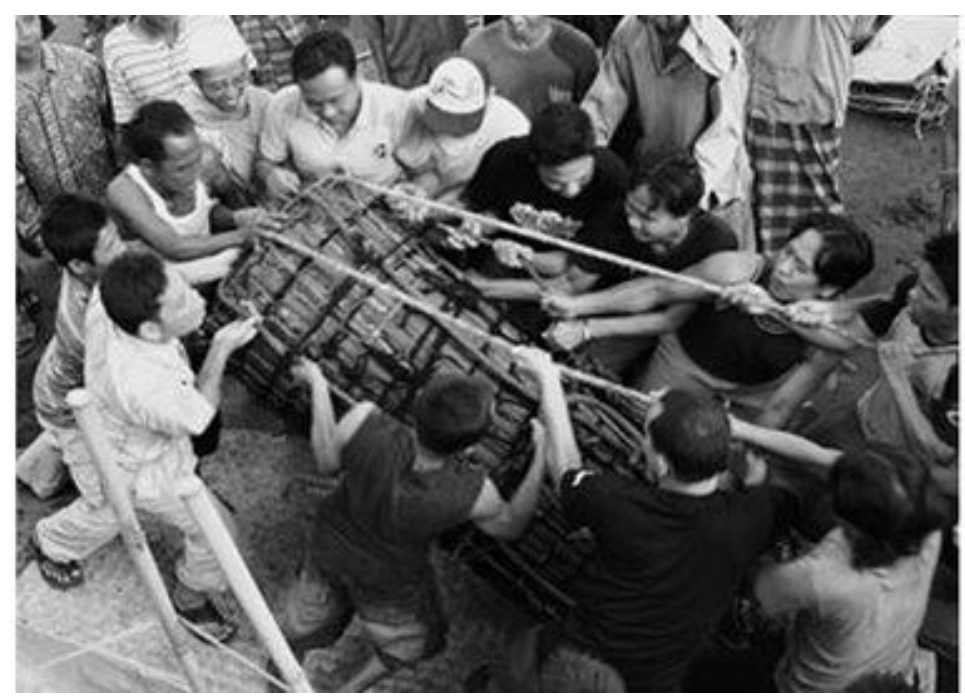

Gambar 2. Pembuatan Lopis Raksasa secara Gotong Royong oleh Pemuda Setempat Sumber: internet

Para pemuda Krapyak, khususnya di Gang 8 atau dikenal juga dengan Gang Sumbawan bergotong royong membuat lopis raksasa. Pembuatan lopis ini sekitar empat hari tiga malam, disesuaikan dengan ukuran lopis. Makin besar ukurannya, makin lama pula proses pembuatannya. Pemuda setempat membentuk kepanitiaan dan mendapat tugas masing-masing. Lopis raksasa merupakan momen yang ditunggu-tunggu pemuda setempat lantaran adanya lopis ini mampu merekatkan kembali para pemuda. Mula-mula beras ketan dicuci bersih sebanyak dua kali, beras ketan yang sudah dicuci direndam di dalam air sekitar 10 hingga 15 menit, dan ditiriskan hingga kadar air berkurang. Beras ketan yang sudah ditiriskan dimasak setengah matang, kemudian beras ketan ditumbuk sampai kalis, adonan yang sudah kalis dimasukkan dalam daun pisang yang sudah ditata dengan penyangga bambu, setelah itu lopis yang setengah matang ini dimasukkan dandang dengan menggunakan katrol. Lopis dimasak dengan tungku tradisional, mengingat ukuran yang raksasa tidak memungkinkan menggunakan kompor. Pembuatan tungku juga unik, yaitu dengan melubangi tanah untuk memasukkan kayu bakar. Lopis dimasak sekitar satu hari satu malam kemudian diangkat dan dibalik agar lopis matang sempurna. Pembalikkan lppis ini dilakukan secara bergotong royong menggunakan katrol. Lopis dimasak lagi sampai benar-benar matang ${ }^{10}$.

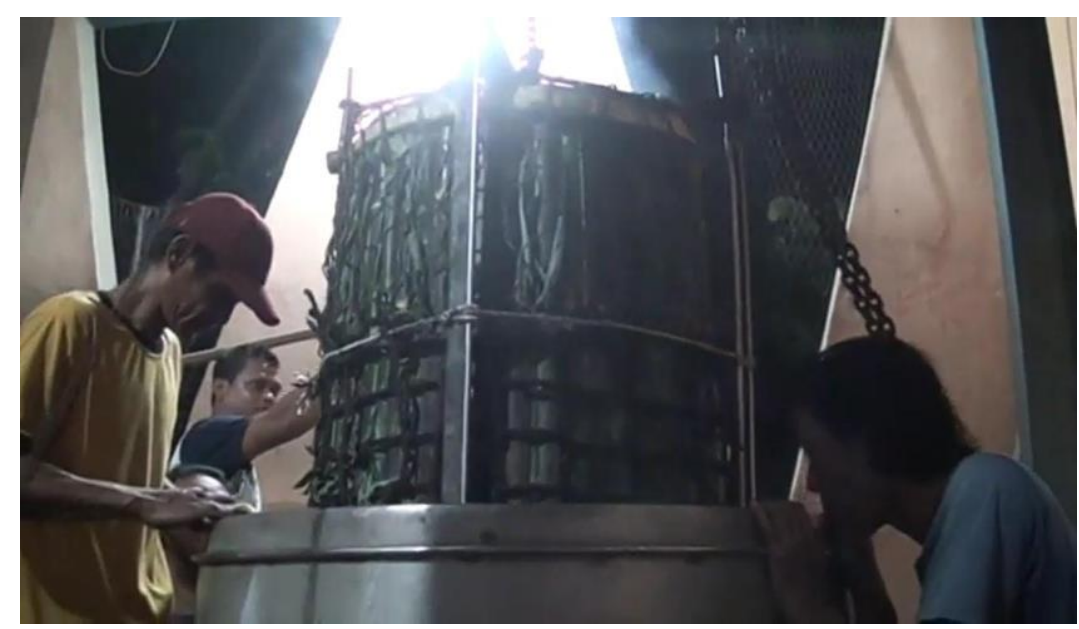

Gambar 3. Lopis Raksasa akan dimasukkan dalam dandang menggunakan katrol

${ }^{10}$ Wawancara dengan warga setempat, Iwan Kurniawan, 6 Juni 2021 
Sumber: Dokumen pribadi warga setempat, Iwan Kurniawan.

Upacara tradisi lopis raksasa menjadi destinasi wisata budaya masyarakat Pekalongan dan sekitarnya. Banyak pengunjung yang memercayai jika lopis raksasa membawa berkah bagi konsumennya. Kepercayaan ini termasuk dalam tabarukan atau kepercayaan orang-orang mengenai berkah Tuhan yang mewujud melalui perantara benda. Dalam hal ini benda yang dimaksud adalah lopis raksasa. 'Berkah' atau 'barokah' yang dimaksud merupakan konvensi untuk mewakili keluarbiasaan lopis. Proses pembuatan lopis tidak hanya sekadar membuat lopis mengikuti alur proses pembuatan, tetapi ada tahaptahap tertentu, seperti didoakan ${ }^{11}$.

Berdasarkan penelitian yang telah dilakukan melalui observasi, wawancara, dan studi pustaka ternyata lopis raksasa yang dibuat pemuda Krapyak, Pekalongan, tidak sembarang dibuat begitu saja. Ada tahap-tahap tertentu yang lekat dengan nilai-nilai spiritual. Berikut nilai-nilai spiritual yang ditemukan dalam proses pembuatan lopis raksasa, nilai spiritual yang melekat pada lopis, dan pada saat upacara pemotongan dan pembagian lopis.

\section{NILAI-NILAI SPIRITUAL LOPIS RAKSASA PADA SAAT PROSES PEMBUATAN}

\section{a. Pembuat Lopis Raksasa Dianjurkan untuk Bersuci}

Setiap pembuat lopis raksasa yang didominasi oleh pemuda Gang 8, Krapyak atau pemuda Gang Sumbawan dianjurkan untuk bersuci terlebih dahulu. Hal ini diungkapkan oleh ulama setempat, KH. Zainudin Ismail pada wawancara semiterstruktur yang dilakukan pada 13 Juni 2021. Bersuci yang dimaksud adalah dengan berwudu. Wudu merupakan upaya penyucian diri, biasanya dilakukan sebelum melakukan ibadah dengan membasuh muka, tangan, kepala, dan kaki. Salah satu manfaat dalam keadaan suci adalah sebagai upaya menjaga diri dari perilaku atau perbuatan yang tidak-tidak.

Wudu memiliki banyak manfaat, seperti (1) wudu dapat menenangkan jiwa dan membuat pikiran lebih bisa berkonsentrasi. Efek sejuk yang didapat pada saat mengusap kepala mampu membuat pikiran menjadi tenang. Para ahli neurologis atau ahli syaraf telah membuktikan bahwa wudu mampu memantapkan konsentrasi melalui sensasi sejuk yang didapat ketika membasuh tubuh. (2) Wudu mampu meredakan emosi, sesuai dengan hadis riwayat Abu Daud yang memiliki makna "Sesunggubnya marah itu dari setan dan sesungguhnya setan diciptakan dari api. Dan sesunggubnya api itu dipadamkan dengan air. Maka jika seseorang dari kalian sedang marah, maka berwudulah.” (HR. Abu Daud). Pembuatan lopis raksasa ini dilakukan oleh banyak orang secara gotong royong sehingga para pembuat lopis diupayakan menjaga kondisi agar tidak terpacu emosi. Salah satu upaya untuk tetap merilekskan pikiran agar tidak menegang adalah dengan berwudu terlebih dahulu. (3) Wudu yang dilakukan secara khusyuk dapat menumbuhkan persepsi dan energi positif. Orang-orang yang berpikiran positif dan memancarakan energi positif akan tersalurkan pada lingkungan sekitarnya, dalam hal ini adalah lopis raksasa yang sedang dibuat. Manusia adalah makhluk penyerap. Makanan yang dibuat dengan pikiran positif akan terserap pula pada makanannya dan tersalurkan kepada konsumen makanan tersebut. (4) Wudu mampu menjadi upaya menjaga kebersihan, bagian-bagian tubuh yang dibasuh saat berwudu merupakan bagian yang terbuka dan dikhawatirkan terdapat kuman atau bakteri tertentu. Dengan berwudu, kuman dan bakteri tersebut terminimalisir ${ }^{12}$.

11 Wawancara budayawan Pekalongan, Ribut Achwandi, 1 Juni 2021

${ }^{12}$ M. A Ahmad. 2003. EKSPERIMEN AHLI HIKMAH TERHADAP AYAT-AYAT

MUJARRABAT. ALQALAM, 20(96). https://doi.org/10.32678/alqalam.v20i96.654 dan Lela. 2016. 


\section{b. Diawali dengan Membaca Basmalah}

Berdasarkan wawancara yang dilakukan kepada tokoh agama Krapyak, Pekalongan, KH. Zainudin Ismail, para pembuat lopis mula-mula membaca basmalah terlebih dahulu. Dalam ungkapnya, membaca basmalah memiliki banyak keutamaan seperti mendatangkan berkah.

"Proses pembuatan lopis diawali dengan membaca basmalah. Sengaja dianjurkan membaca basmalah karena ada keutamaannya. Apalagi kalau mendhawamkan (membiasakan) membaca basmalah bisa membawa berkah.”.13

Keutamaan lain membaca basmalah, yaitu membaca basmalah dapat memudahkan hal-hal yang sulit, mendatangkan rezeki, dan melindungi dari gangguangangguan ${ }^{14}$. Maksud dari membaca basmalah ini adalah suatu tahap melibatkan Allah Swt. sebagai wujud bahwa manusia yang dalam hal ini adalah seorang hamba tidak mampu berbuat apa-apa kecuali rida dan ketetapan-Nya.

\section{c. Diakhiri dengan Membaca Hamdalah}

Kebiasaan membaca hamdalah dibudayakan oleh masyarakat Krapyak yang didominasi oleh kaum muslim usai mengerjakan apa pun. Para pembuat lopis raksasa membaca hamdalah atau pujian kepada Allah usai proses pembuatan. Hal ini sesuai dengan hasil wawancara yang ditanyakan kepada ulama setempat, KH. Zainudin Ismail.

"Setelah lopis raksasa selesai dimasak, lalu diangkat dari dandang besar menggunakan katrol, sekarang pakai katrol, kalau diangkat bareng-bareng pakai tambang, padabal beratnya seribu kilo lebih, terus diangkut dibawa ke depan TPQ Miftahul Ulum para pembuat lopis mengucap alhamdulillah bersama-sama sebagai wujud syukur karena bisa membuat lopis raksasa sampai selesai dengan selamat. Membaca alhamdulillah juga mendatangkan rida Allah.”. ${ }^{15}$

Membaca hamdalah termasuk dalam budaya religius yang hendaknya terus dilestarikan karena merupakan wujud syukur dari makhluk kepada Allah Swt. Membaca hamdalah memiliki keutamaan atau manfaat lain, seperti diampuni kesalahannya, ditambah rezekinya sesuai dengan firman Allah dalam Q.S. Ibrahim ayat 7 yang artinya "Dan (ingatlah juga), tatkala Tubanmu mengumumkan, 'Sesunggubnya jika kamu bersyukur, pasti Kami akan menambah (nikmat) kepadamu, dan jika kamu mengingkari (nikmat-Ku), maka sesunggubnya azab-Ku sangat pedih." ${ }^{\prime \prime \prime}$

\section{d. Membaca Selawat}

Pembacaan selawat secara bersama-sama dilakukan oleh para pembuat lopis. Kebiasaan membaca selawat ini dianjurkan oleh KH. Zainudin Ismail (13 Juni 2021) karena mengandung banyak keutamaan, seperti agar selamat atau tidak terjadi hal yang tidak-tidak selama proses pembuatan. Selawat yang kerap dilantunkan para pembuat lopis adalah selawat burdah, karangan Imam Bushiri dengan syair berbahasa Arab ${ }^{17}$

\footnotetext{
KETENANGAN" : MAKNA DAWAMUL WUDHU (Studi Fenomenologi Pada Mahasiswa UIN

Raden Fatah Palembang). Psikis : Jurnal Psikologi Islami, 1(2).

13 Wawancara KH. Zainudin Ismail, 13 Juni 2021

${ }^{14}$ M. A Ahmad, op. cit

15 Wawancara KH. Zainudin Ismail, 13 Juni 2021

16 Ardi. 2020. ALHAMDULILLAH DALAM AL QURAN (Kajian Terhadap Lafadz Al-

Hamdulillah Dalam Fawatih dan Khawatim As-Suwar). Al-Misykah: Jurnal Kajian Al-Quran Dan Tafsir, 1(02), 25-135.

${ }^{17}$ E Setiawan. 2015. Nilai-Nilai Religius dalam Syair Shalawat Burdah. Lingua: Jurnal Ilmu Bahasa Dan Sastra, 10(1).
} 
(Setiawan, 2015), ya Robbi bil musthofa baligh maqooshidanaa, wagfir lanaa maa madho yaa waasial karoomi. Syair tersebut mengandung pujian-pujian yang dihaturkan kepada Rasulullah Saw., doa-doa yang berisi harapan-harapan dikabulkan oleh Allah Swt., dan permohonan ampun kepada Allah Swt.

Selawat merupakan zikir Ilahi yang mampu mendekatkan manusia kepada Tuhannya. Selama proses pembuatan lopis raksasa, para pembuatnya bisa saja diliputi rasa bosan sehingga selawat mampu menjadi media hiburan dan pengalih obrolan yang kurang bermanfaat seperti bergosip ${ }^{18}$.

\section{NILAI-NILAI SPIRITUAL YANG MELEKAT PADA LOPIS RAKSASA}

\section{a. Lopis Raksasa Terbuat dari Beras Ketan}

Beras ketan memiliki tekstur yang lengket setelah dimasak. Tekstur lengket ini dikaitkan dengan simbol persatuan dan kerukunan. Lopis menyimbolkan hubungan antarsesama yang saling terikat dan kuat. Gang 8, Krapyak, Pekalongan atau dikenal dengan Gang Sumbawan merupakan gang atau tempat yang dulunya digunakan sebagai tempat persinggahan orang Sumbawa ${ }^{19}$ Oleh karena itu, di gang ini terdapat banyak pendatang dari berbagai daerah, suku, ras, atau agama lain. Persatuan dan toleran dibutuhkan untuk menjaga kerukunan di wilayah ini. Lopis raksasa yang terbuat dari beras ketan merupakan pengejawantahan dari simbol kerukunan antarumat (Rosidin, 2016).

\section{b. Lopis Raksasa Dibungkus Daun Pisang}

Daun pisang yang digunakan untuk membungkus lopis merupakan daun pilihan, yaitu daun pisang batu yang masih segar, tetapi bukan daun pisang yang masih muda. Daun pisang atau dalam bahasa Jawanya godhong gedhang. Gedhang merupakan singkatan dari digeged ben padhang, salah satu falsafah Jawa yang mengandung makna barangsiapa yang bersungguh-sungguh akan beroleh terang ${ }^{20}$. Pemilihan daun ini memiliki makna yang mendalam, yaitu untuk mengingatkan kepada manusia agar bersungguh-sungguh dalam melakukan sesuatu hal.

\section{c. Lopis Raksasa Ditali secara Horizontal dan Vertikal}

Lopis raksasa diikat menggunakan tali tambang melingkar secara horizontal yang mengarah ke atas atau vertikal. Tali seperti ini melambangkan habluminallah dan habluminannas atau melambangkan hubungan manusia dengan sesama makhluk dan hubungan manusia dengan Allah Swt. ${ }^{21}$ Hubungan manusia dengan Allah Swt. juga harus diimbangi hubungan manusia dengan sesama.

${ }^{18}$ A Azizi. 2005. Allah pun Ber-Salawat kepada Nabi: Rahasia \& Keberkahan Salawat Atas Nabi Mubammad SAW. (Zahra Publishing House)

${ }^{19}$ Wawancara dengan warga setempat, Iwan Kurniawan, 6 Juni 2021

${ }^{20}$ Wawancara dengan budayawan Pekalongan, Ribut Achwandi, 1 Juni 2021

${ }^{21}$ Wawancara dengan tokoh agama Krapyak, Pekalongan, KH. Zainudin Ismail, 13 Juni 2021 


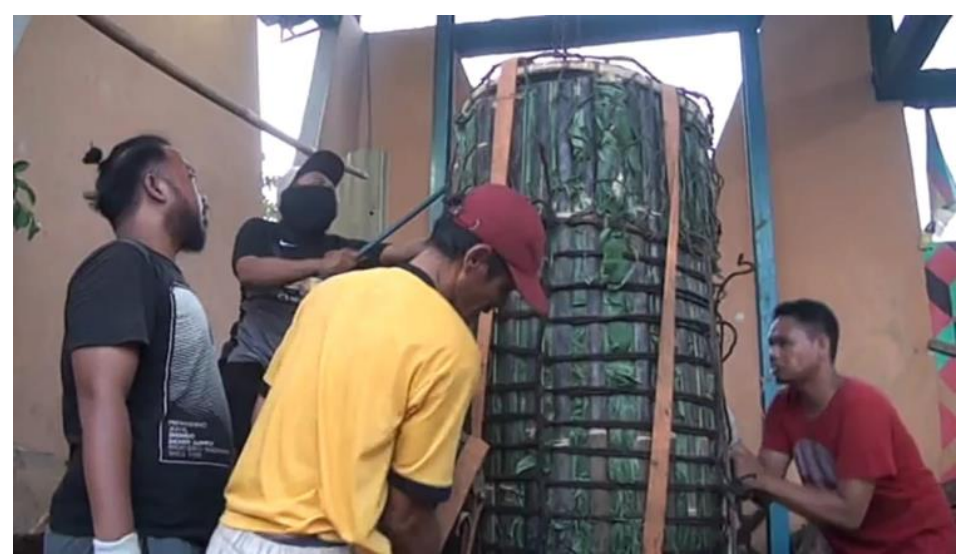

Gambar 4. Lopis Raksasa Ditali secara Horizontal dan Vertikal Sumber: Dokumen pribadi warga setempat, Iwan Kurniawan.

\section{NILAI-NILAI SPIRITUAL LOPIS RAKSASA SAAT DIPOTONG DAN DIBAGIKAN}

Setelah lopis ditempatkan di lokasi yang digunakan untuk upacara tradisi lopis raksasa, yaitu di depan TPQ Miftahul 'Ulum. Lopis raksasa ini didoakan yang dipimpin oleh KH. Zainudin Ismail yang diamini oleh pengunjung dan tamu undangan.

"Doa yang dibaca sebelum lopis dipotong adalah doa meminta keselamatan kepada Allah Swt. agar selama acara diberi kelancaran, selamat, dan aman sampai selesai. Sebelum dipotong dan dibagikan kepada pengunjung, dibacakan bismillah dan selawat nabi baru lopisnya dipotong." ${ }^{2}$

Doa merupakan salah satu wujud keberserahan diri seorang hamba kepada Tuhannya. Lopis yang telah dipotong dibagi-bagikan kepada masyarakat secara cuma-cuma. Pembagian lopis ini merupakan wujud keikhlasan yang dilakukan oleh para pembuat lopis, mereka membuat lopis selama kurang lebih empat hari secara sukarela. Akan tetapi, lopis yang dibuat diperuntukkan kepada orang lain.

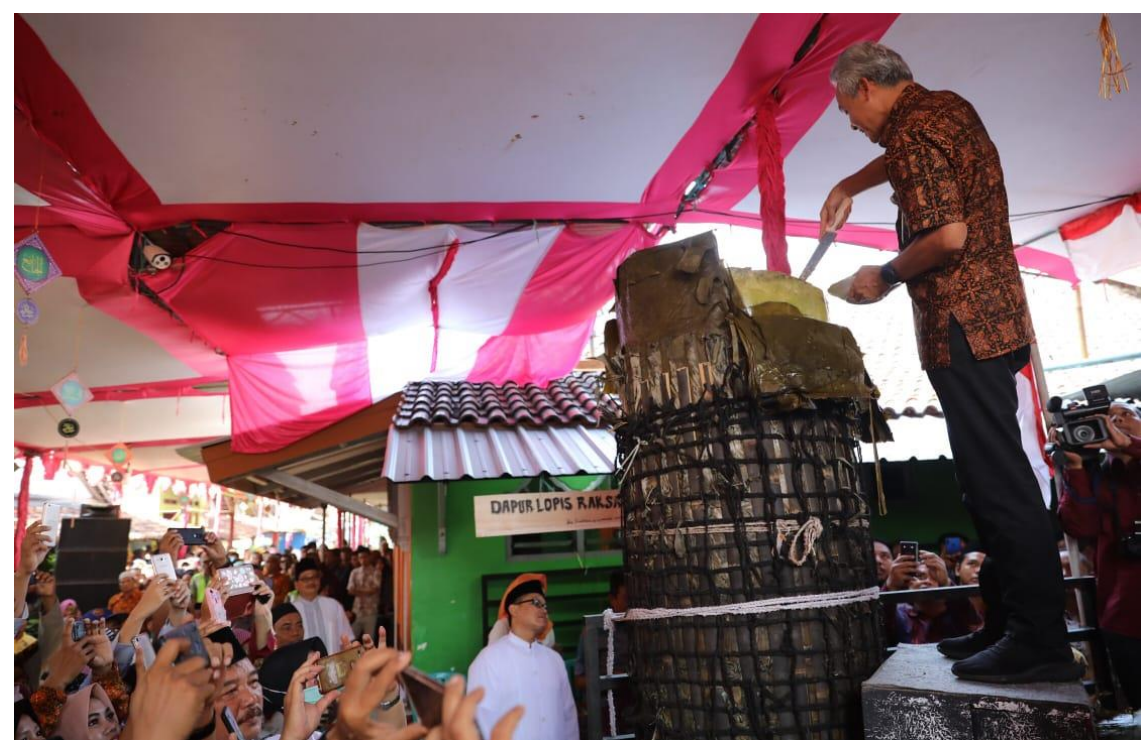

Gambar 5. Lopis Raksasa saat Dipotong oleh Gubernur Jawa Tengah tahun 2019 Sumber: internet.

\footnotetext{
22 Wawancara dengan tokoh agama Krapyak, Pekalongan, KH. Zainudin Ismail, 13 Juni 2021
} 


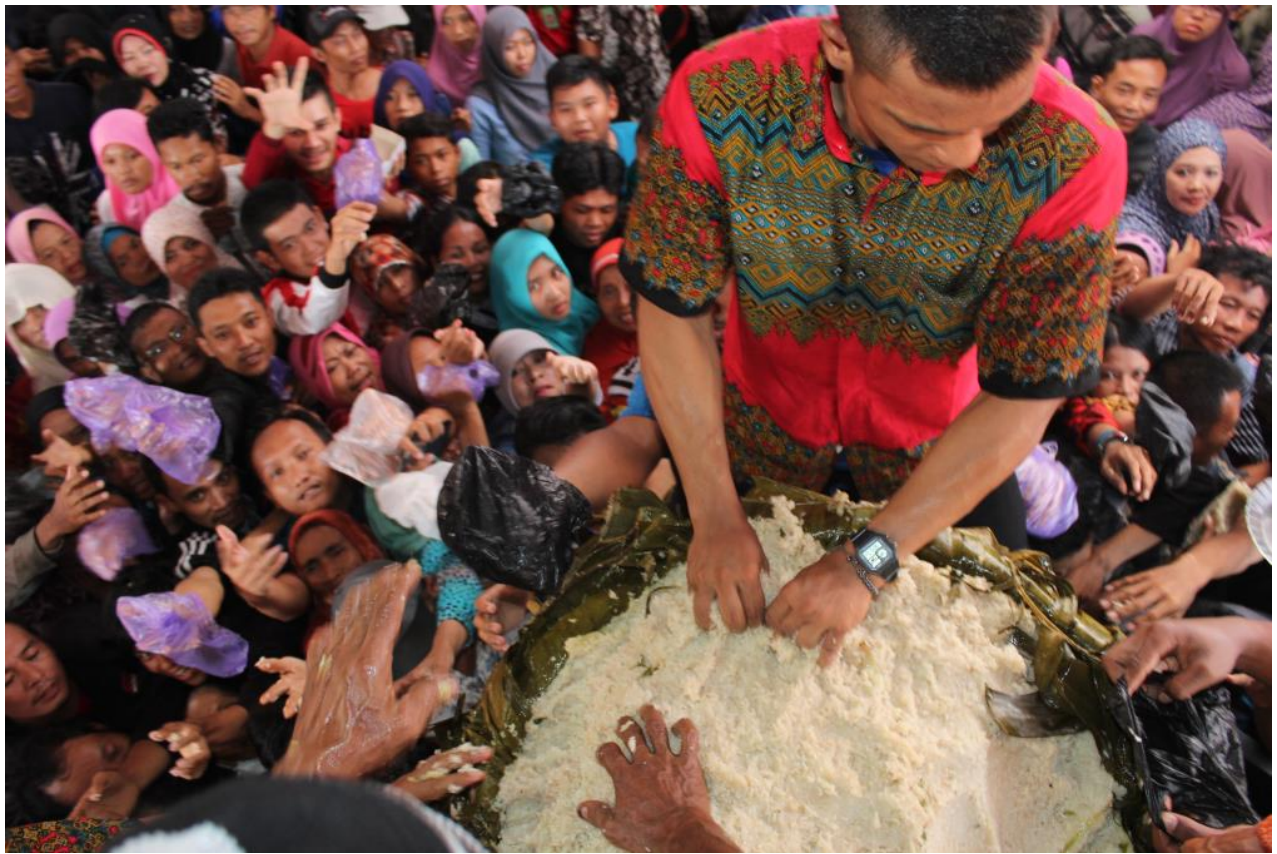

Gambar 6. Pembagian Lopis

Sumber: Depo Arsip Pekalongan, 2018.

Dalam lopis raksasa, terdapat doa-doa baik dari para pembuat dengan harapan doadoa baik tersebut tersalurkan kepada masyarakat atau pengunjung. Salah satu yang membuat lopis raksasa ini istimewa adalah adanya nilai-nilai spiritual yang terkandung di dalamnya. Selain itu, lopis raksasa merupakan budaya yang mewakili religiusitas masyarakat pemilik budaya tersebut. Tidak heran jika pengunjung lopis raksasa berasal dari berbagai daerah, bahkan ada yang dating sehari sebelum upcara pemotongan ${ }^{23}$.

\section{KESIMPULAN}

Dari paparan di bagian hasil dan pembahasan, diketahui bahwa lopis raksasa membawa berkah melalui nilai-nilai spiritual yang terkandung di dalamnya. Nilai-nilai spiritual dalam tradisi lopis raksasa di Pekalongan turut menarik minat warga untuk mengunjungi upacara tradisi tersebut. Nilai-nilai spiritual selama proses pembuatan lopis raksasa, yakni para pembuat dianjurkan bersuci terlebih dahulu, proses pembuatan diawali dengan membaca basmalah, selama proses pembuatan diselawati, dan diakhiri dengan membaca hamdalah. Nilai-nilai spiritual yang melekat pada lopis, yakni menyimbolkan kerukunan antarumat beragama, hubungan manusia dengan sesama, dan hubungan manusia dengan Tuhan. Nilai-nilai spiritual pada proses pemotongan dan pembagian lopis raksasa, yakni ikhlas dan wujud keberserahan diri hamba kepada Tuhan.

\section{REFERENSI}

Ahmad, M. A. 2003. EKSPERIMEN AHLI HIKMAH TERHADAP AYAT-AYAT

MUJARRABAT. ALQALAM, 20(96). https://doi.org/10.32678/alqalam.v20i96.654

Anwar, K. 2013. MAKNA KULTURAL DAN SOSIAL-EKONOMI TRADISI

SYAWALAN. Walisongo: Jurnal Penelitian Sosial Keagamaan, 21 (2).

https://doi.org/10.21580/ws.2013.21.2.253

Ardi. 2020. ALHAMDULILLAH DALAM AL QURAN (Kajian Terhadap Lafadz AlHamdulillah Dalam Fawatih dan Khawatim As-Suwar). Al-Misykah: Jurnal Kajian Al-

${ }^{23}$ wawancara ketua panitia lopis raksasa, Fahruddin, 20 Mei 2021 
Quran Dan Tafsir, 1(02), 125-135.

https://doi.org/https://doi.org/10.19109/almisykah.v1i2.9033

Asmarani, R. 2019. Translating the Unique Folklore of Giant Lopis Feast And Giant Cone Megono In Pekalongan Syawalan Traditions. https://doi.org/10.2991/eltlt-18.2019.18

Azizi, A. 2005. Allah pun Ber-Salawat kepada Nabi: Rabasia \& Keberkahan Salawat Atas Nabi Muhammad $S A W$. Zahra Publishing House.

BPS Kota Pekalongan. 2021. Kota Pekalongan dalam Angka 2021. In BPS Kota Pekalongan (Ed.), Badan Pusat Statistik Kota Pekalongan. BPS Kota Pekalongan.

Lela. 2016. "KETENANGAN": MAKNA DAWAMUL WUDHU (Studi Fenomenologi Pada Mahasiswa UIN Raden Fatah Palembang). Psikis: Jurnal Psikologi Islami, 1(2).

Nuzuli, A. K. 2020. Spasialisasi Sony Music Entertainment Indonesia. Jumal ILMU KOMUNIKASI, 17(1), 123. https://doi.org/10.24002/jik.v17i1.1539

Rosidin, R. 2016. Tradisi Lopis Raksasa dalam Perspektif Kerukunan Umat Beragama di Kota Pekalongan. Al-Ulum, 16(1). https://doi.org/10.30603/au.v16i1.24

Setiawan, E. 2015. NILAI-NILAI RELIGIUS DALAM SYAIR SHALAWAT BURDAH. LiNGUA: Jurnal Ilmu Bahasa Dan Sastra, 10(1). https://doi.org/10.18860/ling.v10i1.3027

Syahputra, H. 2021. RITUAL WUDHU : UPAYA MENJAGA KESEHATAN TUBUH DENGAN PERAWATAN SPIRITUAL. Al-Hikmab: Jurnal Theosofi Dan Peradaban Islam, 2(2). https://doi.org/10.51900/al-hikmah.v2i2.8801

Tim Komunikasi Publik. 2018. Sejarah Singkat Kota Pekalonga.

\section{Wawancara}

Wawancara KH. Zainudin Ismail, 13 Juni 2021

Wawancara dengan warga setempat, Iwan Kurniawan, 6 Juni 2021

Wawancara budayawan Pekalongan, Ribut Achwandi, 1 Juni 2021

Wawancara KH. Zainudin Ismail, 13 Juni 2021

Wawancara dengan budayawan Pekalongan, Ribut Achwandi, 1 Juni 2021

Wawancara dengan tokoh agama Krapyak, Pekalongan, KH. Zainudin Ismail, 13 Juni 2021

Wawancara ketua panitia lopis raksasa, Fahruddin, 20 Mei 2021 